\title{
RESEARCH ON UNDERWATER DIRECTIONAL SWIMMING SKILLS OF DIVERS
}

Bogumił Filipek

Institute of Maritime and Tropical Medicine Polish Naval Academy Gdynia

\section{ABSTRACT}

The article presents the results of research on the application of a physical exercise programme to improve the underwater orientation of military divers. The research was carried out on a group of 120 soldiers, some of whom (the study group) underwent additional training for 3 months. During the underwater straight-line swimming test in poor visibility conditions, the test group achieved statistically significantly better results than the control group. The test consisted in measuring the angle of deviation of the diver's route from the given straight line.

Keywords: diving, underwater orientation, exercises.

\section{ARTICLE INFO}

PolHypRes 2020 Vol. 72 Issue 3 pp. $57-62$

ISSN: $1734-7009$ elSSN: 2084-0535

DOI: $10.2478 /$ phr-2020-0017

Pages: 6, figures: 1 , tables: 1

page www of the periodical: www.phr.net.pl

Publisher

Polish Hyperbaric Medicine and Technology Society
Original article

Published in Yearbook of the Navy Health Service 1981-1982

Acceptance for print: 27.03.2020 r. 


\section{INTRODUCTION}

Correct spatial orientation underwater is important both for the diver and his or her safety and for their ability to perform a combat task. This is shown by the experience of the diver's combat operations during World War II $[5,15]$.

In order to achieve the goal stealthily, the diver has to swim in conditions of limited visibility hundreds or even thousands of metres under water. Orientation is facilitated by a precise depth gauge, compass and a map of the shape of the body of water and possible obstacles. The diver may rely on a depth gauge, while the sketch map may be inaccurate and the compass unreliable [12].

The spatial orientation of a human being is based on the alignment of a complex set of factors determining his or her movement-positioning construct $[4,6,7,9,13]$, which in the case of underwater swimming is disturbed by weightlessness, as well as, to a lesser extent, visibility conditions and density of the ambient environment. The sense of direction is the result of all these factors. However, this skill is individually differentiated, and at the same time it can be developed through appropriate training $[1,2,3,4]$.

The spatial orientation of a human being on land is achieved by a construct, applied and improved throughout one' s life. A completely different situation is experienced by a person in a state of weightlessness and during their stay under water. While moving under water, a diver first of all changes the position of the body from vertical to horizontal, thus confusing his or her normal construct of spatial awareness. They can make use of the organ of sight, but to a very limited extent [14], especially in our latitudes or at night. The kinaesthetic sensations change underwater, as by balancing the diver's body weight he or she obtains a simulated state of weightlessness, allowing him or her to float freely at a certain depth. These factors, together with the specifics of the underwater environment, make it difficult for the diver to maintain the chosen direction of movement.

Bearing in mind the importance of proper directional swimming by divers in the army for the performance of combat tasks, there are few and fragmented reports of this in the literature. [8,12,16].

Therefore, research has been undertaken in order to obtain our own experience in this field, which could form the basis for optimising the model of diver training.

\section{MATERIAL AND METHODS}

The research involved 120 scuba-diving soldiers. The age of the respondents ranged from 19-23 years. All the soldiers were qualified to this specialty by the Military Maritime Medical Commission and they met the health requirements for candidates for military scuba divers. Naturally, all the subjects were able to swim. They were divided into 2 groups:

- I - experimental - consisting of 80 scuba divers, with whom during the 3-month programme an additional proprietary programme of physical exercises was carried out;

- II - control - consisting of 40 divers, who underwent only a 3-month training programme. They were excluded from the specialist physical exercise programme.

The proprietary physical exercise programme was aimed at improving the activities of the scuba divers' balance system, motor coordination during the performance of specific activities, and most of all, the development of spatial imagination under the conditions of a load on the balance system. These exercises, systematically carried out during daily and physical education activities, developed a new, dynamic spatialmotor construct in the divers, allowing them to find their direction more effectively, even when the body position has changed.

After a 3-month programme-training period (group II), a test of underwater directional swimming was carried out with divers from both groups.

Directional swimming under water took place in an isolated sea area of 130x130 m and an average depth of $3 \mathrm{~m}$ [11].

The water temperature during the test was 10 $18{ }^{\circ} \mathrm{C}$. Sea state during the test was between 0 - 1 on the Beaufort scale. Smooth, sandy bottom, steep banks, formed by piers and wooden poles. Visibility in the water during the test was between 0.5 and $2.5 \mathrm{~m}$, depending on water transparency [11]. The diver's field of vision was limited by the diving mask. The test was performed on a cloudy day, without sunlight. The diver was equipped with typical lightweight equipment, a depth gauge and a colour float on the line. The equipment did not include a compass. Prior to descending under water, an examination was carried out for diseases and diving injuries (mainly of the ears), and the diver checked the patency of their otosalpinx by performing the Valsalva manoeuvre. 


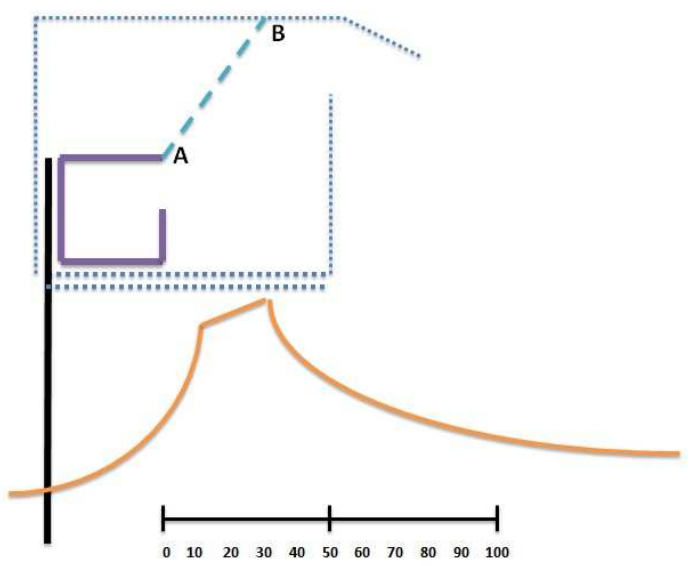

Fig. 1 Body of water for directional swimming tests by divers: A - starting point, B - destination point.

The diver's task was to swim from point $A$ to the opposite point $B$ (Figure 1). The distance from point $A$ to point B was $100 \mathrm{~m}$, the recommended depth was $2 \mathrm{~m}$. The diver, after entering the water and performing a controlled immersion, raised their head above the surface of the water and at point $A$ assessed the visual direction to point $B$, then submerged, descended to a depth of $2 \mathrm{~m}$ and at this depth swam in the previously chosen direction, i.e. to point B. The diver's path was marked on the water by a colour buoy, fixed on a rope to the weight belt, and a trace created by bubbles of exhaled air. This route was marked on a sketch. In the case where the diver was swimming in a circle and was unable to maintain the direction of swimming in a straight line, the test was discontinued. In the case of significant deviation from the designated direction of swimming, the test was terminated after $50 \mathrm{~m}$. During the test, the divers were recommended to maintain normal swimming pace without establishing time regimes. The diver repeated the directional swimming test under water 2 - 3 times.

\section{RESULTS}

The obtained results of the study of directional swimming under water of 80 divers from group I and 40 divers from group II were statistically analysed using the Student's "t" test and are presented in Table 1.

\begin{tabular}{lll}
\multicolumn{3}{l}{ Summary of the results of the underwater directional swimming test of group I and II divers at a distance of $100 \mathrm{~m}}$. \\
\cline { 2 - 3 } Group & Deviation in degrees & To the right \\
\cline { 2 - 3 } I $\ddot{\mathrm{X}}$ & To the left & 12.872 \\
d & 25.94 & 12.872 \\
\hline II $\ddot{x}$ & 13.825 & 53.10 \\
d & 52.63 & 16.392 \\
\hline
\end{tabular}

$\ddot{\mathrm{x}}$ - arithmetic mean, $\mathrm{d}$ - standard deviation. 
The differences in the results achieved by the divers who had completed the additional training programme's special physical exercises and by the divers not performing these exercises are statistically significant $(\mathrm{p}<0.01)$. They confirm the adopted assumption about the possibility of influencing the results achieved in directional underwater swimming training by conducting special physical exercises.

The idea of "adaptive training" for the adaptation of movement in specific conditions has been known for a long time, but despite numerous attempts, to this day this issue has not been satisfactorily resolved. It has been found that people who are professionally involved in physical activity requiring sudden head movements or precise balance, e.g. acrobats, skaters, dancers, gymnasts, are less susceptible to kinetosis than individuals from other professional groups.

Systematic performance of adequate exercise during a month reduced vestibular reactions in $37 \%$ of respondents [17]. The combination of these exercises with swinging on a parallel swing improved these results in $65 \%$, while the use of the Barany's chair and the swing improved these results in as many as $75 \%$ of the respondents [10]. These observations confirm the results of the studies presented, and indicate the expediency of introducing suitably targeted physical exercises to optimise the diver's underwater directional swimming training programme in the various conditions created by combat tasks.

\section{Conclusions}

1. Special physical exercises to improve spatial orientation in difficult conditions improve the diver's performance in directional underwater swimming.

2. The implementation of special physical exercises in the diver's training programme could contribute to raising the level of their combat training.

\section{REFERENCES}

1. nieadekwatnom rozdraznienii Vestibularnoho aparata. Vestn. Otorhinolaryng., 1952, 14, 5 : 19-22

2. in man". Publishing House of Slovak Academy of Sciences, Bratislava 1967: 129-136;

3. Begbie G.H.; Some problems of postural sway. Ciba Foundation Symposium on myotatic, kinesthetic and vestibular mechanisms eds. de Reuck, A. V. S. Knight J. Churchill LTD., London $1967 ; 80-104$;

4. Benson A.J.: Spatial disorientation in flight. Gillies J.A.; A textbook of Aviation Physiology. Ch. 40. Pergamon Press. London 1965;

5. $\quad$ Biskupski S.; Human-torpedoes. Publ. MON. Warszawa 1957;

6. Brandt U., Fluur E., Zylberstein M.; Relationship between flight experience and vestibular function in pilots and nonpilots. Aerospace Med., 1974,$45 ; 1232-1236$

Collins W.E.: Vestibular responses from figure skaters. Aerospace Med., 1966, 37 ; 1098 - 1104;

8. Dęga K., Klajman S.: Comments on the medical security of scuba diving training and combat operations. Lek. Woj., 1968, 44, $10 ; 884-850 ;$

9. Latkowski B., Kubiczkowa J., Jankowski J., Woźniak Z.: Reactions of the balance system during piloting overloads. Med. Lotn., 1974, 44 : 23 29;

10. Łokucijewski B.: Physical training for the prevention of marine sicknesses. Roczn. Sł. Zdr. MW. Gdynia 1973;19-24;

11. Navigational and hydrographic description of the Diver and Scuba Diver Training Centre of the Polish Army's training grounds. For internal use. OSNiP WP, Gdynia 1975

12. Diver's manual. Gdynia 1965;

13. Sobusiak T., Zimny R., Kołaczkowski J., Otulakowski J.: Organisation of extravestibular primary afferent projection from the organ of balance to the brainstem. Roczniki Naukowe, AWF, Poznań 1973, 22 ; 343 - 363;

14. Wapner S., Witkin H.A. The role of visual factor in the maintenance of body balance. Am. J. Psychol., 1950, 63. $3: 385-408$

15. Woytt J.M.: Dywizjon żab. Wyd. MON. Warszawa 1959;

16. Vorosmarti J., Yanowski N.: Raport “The diving medicine research program of the US Navy”. Bethesda 1974;

17. Vozzova A.J., Okuniev P.A.: Ukacivanije I borba s nim. Medicina, Leningrad 1964;

dr Bogumił Filipek

Instytut Medycyny Morskiej i Tropikalnej WAM Gdynia 